\title{
INFLUENCE OF VARYING SOIL PROPERTIES ON EVALUATION OF PILE RELIABILITY UNDER LATERAL LOADS
}

\author{
Janusz Kozubal ${ }^{1}$, Wojciech Puła ${ }^{2}$, Marek Wyjadłowski ${ }^{3}$, Jerzy Bauer ${ }^{4}$ \\ ${ }^{1,2,3}$ Faculty of Civil Engineering, Wroclaw University of Technology, Wybrzeze St. Wyspianskiego 27 \\ 50-370, Wroclaw, Poland \\ ${ }^{4}$ Faculty of Mining, Geoengineering and Geology, Wroclaw University of Technology, Wybrzeze St. \\ Wyspianskiego 27 50-370, Wroclaw, Poland \\ E-mails: ${ }^{1}$ janusz.kozubal@pwr.wroc.pl; ${ }^{2}$ wojciech.pula@pwr.wroc.pl (corresponding author); \\ ${ }^{3}$ marek.wyjadlowski@pwr.wroc.pl; ${ }^{4}$ jerzy.bauer@pwr.wroc.pl
}

Received 22 Sep. 2012; accepted 26 Nov. 2012

\begin{abstract}
A three dimensional probabilistic approach to analyzing laterally loaded piles is presented. Two typical subsurface models are used in the analyses: the first one consists of layered linear elastic soil where each layer has a random modulus of elasticity; while the second model takes the form of linear elastic soil with a random modulus of elasticity that increases with depth. Efficient step by step procedures for the reliability computation involving pile displacements are proposed. The solution is based on three-dimensional modeling by the finite element method. A series of results has been obtained for various values of elastic parameters of the soil. Next by a non-linear regression procedure a response surface is obtained. To get the final response surface allowing for a reliability analysis, an iterative algorithm based on the so-called design point concept is applied. The failure criterion is defined as the pile head displacement exceeding displacement threshold. The two cases of piles subjected to lateral load are computed. The paper illustrates the influence of the two distinct types of subsurface variability on the probabilistic analysis. A pronounced effect of the random variability of both the lateral force and the elastic modulus of the upper layer on reliability indices has been shown in results of numerical examples.
\end{abstract}

Keywords: reliability, optimization, probabilistic method, pile under lateral loads.

Reference to this paper should be made as follows: Kozubal, J.; Puła, W.; Wyjadłowski, M.; Bauer, J. 2013. Influence of varying soil properties on evaluation of pile reliability under lateral loads, Journal of Civil Engineering and Management 19(2): 272-284.

\section{Introduction}

A subsoil investigation using exploratory boring to examine the geological strata usually reveals one of two kinds of varying subsurface conditions. The first case consists of different layers that have contrasting elastic and strength parameters. In the second case, which is also important from the designing viewpoint, a single weak layer that can be considered as morphologically homogenous is placed on a strong layer. In our work, elastic properties of the soft strata will be assumed as the random variables and a Young's modulus of the underlying stiff layer, if any occurs, will be regard as a deterministic one. For samples from the first case, laboratory testing produces parameters of Young's modulus random distributions for each particular soil layer. Soil sampling from the second case may reveal random elastic modulus varying with depth even though the layer is morphologically homogenous.

Both ultimate and serviceability limit states apply to the situation of a pile with a transverse loading component. For the case in which ultimate limit state is under consideration, the deciding factor is the bearing capacity of the soil in relation to the lateral pile pressure.

The goal of this study is to show the effect of the two types of varying subsurface conditions mentioned above on calculation procedures evaluating the reliability of a pile laterally loaded under limit serviceability state given by condition $U\left(X_{\mathrm{i}}\right)<u_{0}$. In this condition $U\left(X_{i}\right)$ denotes a displacement of a pile head dependent on random variables $X_{i}$ and $u_{0}$ is an allowable threshold with the value recommended by standards. The focus of the paper is a single pile subjected to lateral loads.

Brinch Hansen (1961), Broms (1964a, b) and Poulos (1971) have proposed classical solutions applied in design practice. Recent papers considering piles subjected to lateral loads concern both bearing capacity problems as well as pile displacement in surrounding subsoil. Examples of important cited works in this area include papers by Reese (1997), $\mathrm{Xu}$ and Poulos (2001), Ashour and Norris (2003), Yang and Jeremić (2005), Guo (2006), Basu et al. (2009) and Zhang (2009). Extensive overviews of the 
computational methods within this subject are given in the book by Reese and Van Impe (2001) as well as in the paper by Fan and Long (2005).

Numerical methods are now the most common tool in determining the capacity of piles under transverse loading. Considering the relatively large sensitivity of pile bearing capacity and displacements on the variation of subsurface parameters as well as loading, numerical deterministic analysis alone may be inadequate. Relative variability of subsurface and load conditions should be considered while including probabilistic methods in the analysis.

A probabilistic analysis of the ultimate capacity of laterally loaded rigid piles based on the classical Brinch Hansen (1961) approach has been carried out by Puła et al. (1997, 2005, 2007).

In most cases, from the point of view of the designer, the limiting condition that governs the design procedure is most significant. The constraints state that the horizontal displacement at the pile head from transverse loading as well as the maximum bending moment must not exceed an allowable value. One of the important contributions to addressing this problem in conjunction with the probabilistic approach is presented in the paper by Tandjiria et al. (2000). The paper provides a probabilistic analysis concerning the risk of pile head displacements as well as the maximum bending moments, which did not exceeded allowable values. To enable the computation, relevant probability measures using the response surface method based on the widespread $p-y$ curve analysis (McClelland, Focht 1956; Matlock 1970) were applied. In the evaluation, the effect of possible changes in soil properties "with depth" was incorporated. The probability distributions of pile head displacements and of the greatest bending moment have been estimated by means of the Monte Carlo simulation. However, the solutions given by these authors are restricted to a one-dimensional approach and normal distributions of soil properties.

In the paper by Haldar and Sivakumar Babu (2008), the properties of soil surrounding the pile have been characterized by non-Gaussian random fields according to the suggestions of Fenton and Griffiths (2003, 2008). This approach allows incorporating the spatial variability of soil parameters into reliability computations. The numerical analysis utilized the finite difference method and the joint probability distributions of pile head displacements and the maximal bending moment were evaluated by applying the Monte Carlo method. In this case, solutions were restricted to two-dimensions.

In the paper by Chan and Low (2009) an analysis in the context of reliability computations were carried out. The procedure presented involves nonlinear pile flexural rigidity with nonlinear $p-y$ curve analysis. The paper investigates two modes of failure: deflection and bending moment. The reliability computations incor- porate the FORM (Ditlevsen, Madsen 1996) approach and use a spreadsheet based numerical procedure. In addition, the response surface method was applied as an alternative supporting the reliability computations.

The study presented below shows a probabilistic three-dimensional approach based on the linearly elastic model. The probabilistic modeling focuses on pile head displacements caused by lateral forces. The procedures are relevant to the two cases of layered subsoil mentioned in the beginning of this introduction. Namely, two subsurface conditions are evaluated with the first consisting of layered linear elastic soil with each layer having a random modulus of elasticity while the second condition takes the form of a linear elastic soil with a random modulus of elasticity increasing with depth. In both cases, the pile reaches soil with good elastic and strength parameters. The input data to calibrate the response surface was obtained by using three-dimensional modeling with the help of finite element method (FEM). The evaluation of relevant reliability measures was conducted using the response surface method (Myers, Montgomery 1995) for which an especially dedicated algorithm was constructed. Then the second order reliability method (Hohenbichler et al. 1987) was utilized in order to determine the results.

The two presented computations of piles subjected to lateral load illustrate the influence of the two distinct types of subsoil variability on the probabilistic analysis.

\section{Varying subsurface elasticity parameters for the two soil profiles}

The layered subsoil used in the first numerical model, shown in Figure 1, has a constant value of the expected modulus of elasticity for each respective layer. In addition, Poisson's ratio is assumed to be deterministic and have a constant value.

The second subsoil model under consideration assumes that the Young's modulus of the weak layer increases with depth. It should be emphasized, however, that consensus is lacking in literature about varying physical and mechanical properties with depth. This topic is discussed in detail by Cherubini (1997, 2000). Li et al. (1987) propose three different models of random soil strength and mechanical parameters varying with depth as shown in Figure 2. In the figure, the continuous lines show expected values and dotted ones their variability ranges:

- Type a: the average and standard deviation do not change with depth;

- Type b: the average value changes linearly with depth while the standard deviation remains constant;

- Type c: the average value and standard deviation increase linearly with depth.

The present study assumes the third type of statistical description with the average value and 


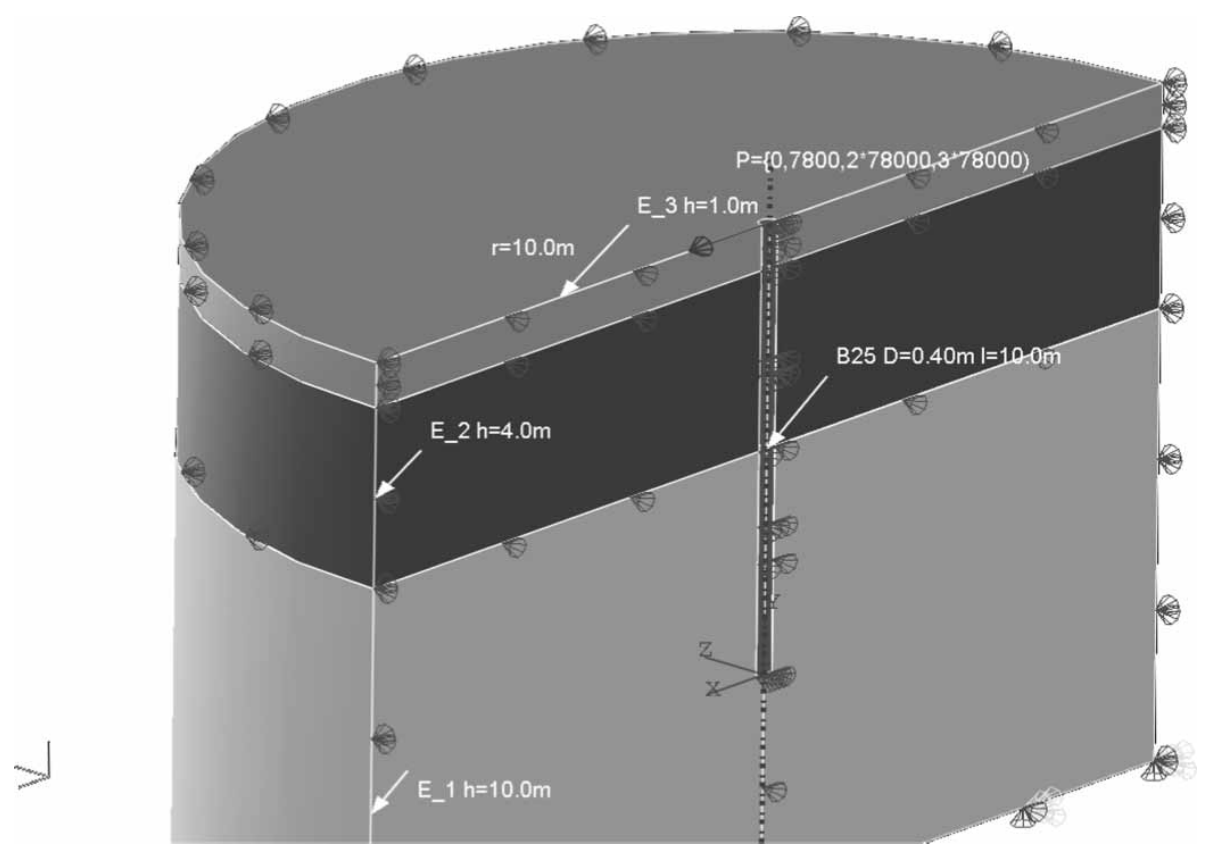

Fig. 1. The layered subsoil used in the first numerical model

standard deviation increasing linearly with depth. In the model represented by Type c, Young's modulus for the weak layer is described by the following relationship:

$$
E=E_{0}+k z
$$

where: $E_{0}$ is a random variable, lognormally distributed, describing Young's modulus at near the surface; $k$ is a parameter describing the increase of the modulus $E_{0}$ and is assumed to be a random variable with a normal distribution; $z$ is depth. Moreover, the expected value of the random variable $E$ changes with depth according to the following equation:

$$
\mathrm{E}[E]=\mathrm{E}\left[E_{0}\right]+\mathrm{E}[k] z
$$

where: $\mathrm{E}[E]$ - expected value of Young's modulus at depth $z ; \mathrm{E}\left[E_{o}\right]$ - expected value of Young's modulus at near the surface; $\mathrm{E}[k]$ - expected value of the elastic modulus gradient.
The random variables $E_{0}$ and $k$ can be often correlated, although, it is necessary to perform statistical tests on samples to determine if this is the case. As a consequence of Eq. (1), the variance of random variable $E$ is given by:

$$
\operatorname{Var}[E]=\operatorname{Var}\left[E_{0}\right]+\operatorname{Var}[k] z^{2}+2 z \operatorname{Cov}\left[E_{0}, k\right],
$$

where:

$$
\operatorname{Cov}\left[E_{0}, k\right]=\mathrm{E}\left\{\left[E_{0}-\mathrm{E}\left[E_{0}\right][\mathrm{k}-\mathrm{E}[\mathrm{k} \rrbracket\}\right.\right.
$$

is the covariance of random variables $E_{0}$ and $k$. If $E_{0}$ and $k$ are uncorrelated then the coefficient of variation of $E$ takes the form:

$$
\nu_{E}=\frac{\sqrt{\operatorname{Var}[E]}}{\mathrm{E}[E]}=\frac{\sqrt{\operatorname{Var}\left[E_{0}\right]+\operatorname{Var}[k] z^{2}}}{\mathrm{E}\left[E_{0}\right]+\mathrm{E}[k] z} .
$$

This way the coefficient of variation is a function of depth.

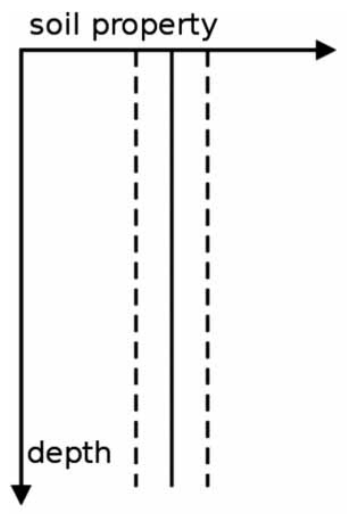

a)

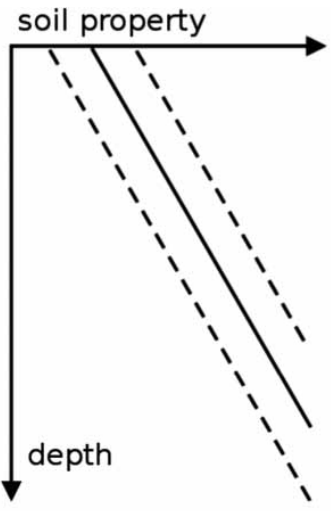

b)

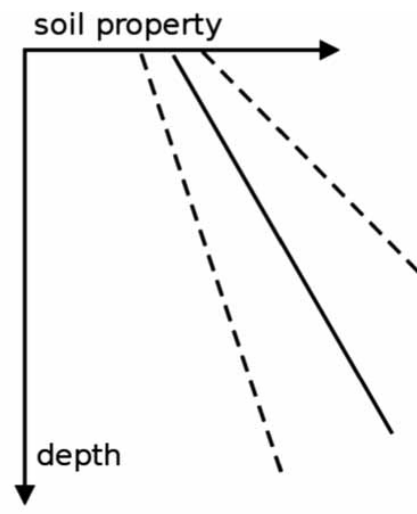

c)

Fig. 2. Three models of random soil strength and mechanical parameters 


\section{Estimating stochastic parameters of randomly distributed variables}

Stochastic parameters of randomly distributed variables can be determined by in situ subsurface testing as well as by laboratory testing of samples obtained from different depths.

With an adequate number of samples from each layer, the expected value and the type of distribution for the random variable of the modulus $\mathrm{E}$ can be estimated. Due to thermodynamic limits, the random variable of the modulus cannot take negative values. Thus, one of the probability distributions to consider is the lognormal distribution.

For a morphologically homogenous subsoil layer, when the estimated elastic modulus $E$ depends on the sample depth, elaborating of laboratory test data is more complex. In this study, the regression method is used with the aid of the software tool NLIN2 (Marquardt 1966) to obtain values of stochastic parameters for the subsurface model with Young's modulus varying with depth. The procedure for getting these values is described as follows. Any function $U(\mathbf{X})$ can be estimated using nonlinear regression model introduced by the following equation:

$$
\mathrm{E}(U)=f(\mathbf{X}, \mathbf{B})+e r r,
$$

where: $f$ is an elementary function having an assumed form; $\mathrm{E}(U)$ is the expected value of variable $U ; \mathbf{X}$ is a vector with $m$ arguments; $\mathbf{B}$ is a vector with $k$ unknown parameters of the regression model to be calculated; and err is the random variable describing the error in estimating the function $U$. The parameter values of vector $\mathbf{B}$ are calculated by minimizing the sum of squares of the difference between the value of function $U_{i}$ and its predicted value $\hat{U}_{i}$ :

$$
\Psi=\sum_{i}^{n}\left(U_{i}-\hat{U}_{i}\right)^{2}
$$

for $n$ data sets: $\left(U_{i}, X_{i l}\right), i=1,2, \ldots, n, l=1,2, \ldots, m$. The expected value of the random variable err is zero and the standard deviation is calculated as follows:

$$
\sigma_{e r r}=\sqrt{\frac{\Psi_{\min }}{n-k}} .
$$

The minimum function $\Psi$ is most often found by the linearization method or the method of steepest descent (Marquardt 1963). The program NLIN2 (Marquardt 1966) used in this study employs the latter method. For statistical elaboration of the test data showing increase of Young's modulus on depth the model Eq. (1) was utilized.

The program NLIN2 treats the calculated estimated parameters of regression as random variables with a normal distribution and provides the expected value of the modulus $E_{0}$ and the gradient $k$ along with their respective standard deviations. In addition, the program provides a correlation matrix of the random variables $E_{0}$ and $k$ together with their confidence intervals. From the confidence interval for the gradient $k$, it is possible to verify the dependence Eq. (1) of the elastic modulus on depth. For the case in which the confidence interval of the gradient $k$ includes zero, on assumed statistical significance level, the elasticity of the layer may only be described by the random variable $E_{0}$ and thus the model in Eq. (1) cannot be applied.

If the model Eq. (1) passes significance testing, there is an additional calculation step. It is commonly held that the modulus $E_{0}$ is lognormally distributed (Fenton, Griffiths 2008). Thus, it is necessary to convert the modulus $E_{0}$ from the obtained normal distribution to lognormal distribution (by the method of moments or by the least square method). The gradient $k$ representing the changing elastic modulus may take a negative value meaning that Young's modulus decreases with depth. This is also the reason the distribution of the gradient can be normal. Although when performing the FEM and probability calculations, it is necessary to check if the elastic modulus from Eq. (1) is positive throughout layer thickness, having varying elastic modulus.

\section{Modeling using finite element analysis}

When employing the response surface method (RSM) (Myers, Montgomery 1995; Faravelli 1989) to compute reliability measures of a transversely loaded pile under serviceability limit state conditions, there is a need to get data of the horizontal displacements at the pile head dependent on a group of random variables including the loading intensity, the elastic modulus, and the gradient representing an increasing Young's modulus with depth. Some information can be drawn from in situ soil testing. However, currently, numerical modeling is used as a supporting tool in order to obtain the required data for the response surface method (RSM).

In this study, the example calculations will be conducted for two soil profiles. The first calculation model is for a loaded pile in multilayered, linear elastic soil that has circular symmetry (see Fig. 2). The diameter and thickness of the calculation model are $20.0 \mathrm{~m}$ and $15.0 \mathrm{~m}$, respectively. The axis of symmetry of the system is located at the center of a single pile having a diameter of $\mathrm{D}=0.40 \mathrm{~m}$. The pile length is $10.0 \mathrm{~m}$. Transverse loading and subsequent deformation at the pile head causes the system to lose its symmetry about the pile center. This leads to threedimensional modeling, although the calculation model with the loaded pile has a single plane of symmetry. The both FEM models are a physically nonlinear due to possible slippage and open crack at the pile-soil contact surface. Soil particles are glued to pile 
concrete unless cohesion due to Mohr-Coulomb slip condition is fulfilled. No tensile stresses are allowed at the contact surface. When shear stresses at pile-soil interface exceed strength of the joint slippage occurs.

The first subsurface model takes the form of the multilayered system displayed in Figure 1:

- layer 1, thickness $10.0 \mathrm{~m}$, pile penetration in this layer is $5.0 \mathrm{~m}$ (to bottom of pile);

- layer 2, thickness $4.0 \mathrm{~m}$ (pile passes completely through);

- layer 3, thickness $1.0 \mathrm{~m}$ (at the ground surface).

As indicated, the applied loading and subsequent displacement produces a plane of symmetry allowing half of the original cylindrical model to be used in FEM calculations with proper boundary condition for displacement. In the model, all layers are defined as being ideally linear elastic with mean value of Young's modulus $E=60.0 \mathrm{MPa}$, unit weight $\gamma=18.0 \mathrm{kN} / \mathrm{m}^{3}$ and Poisson's ratio $v=0.25$. However, for the purpose of probabilistic computations, several computation runs with Young's modulus expected values varying in the range of $E=42.0-78.0 \mathrm{MPa}$ have been carried out for first FEM model. The pile used in the both analyses is assumed to be a concrete pile having following properties: unit weight $\gamma=24.0 \mathrm{kN} / \mathrm{m}^{3}$, Young's modulus $E_{b}=30.0 \mathrm{GPa}$ and Poisson's ratio $v=0.2$. The contact surface between the pile and soil is assumed to have a coefficient of friction of $\mu=0.3$ and applied only in compression.

Three magnitudes of transverse loading $F$ (156, $312,468 \mathrm{kN}$ ) at the pile head are used to check for linearity of a displacement-applied force relationship. The force magnitude of $312 \mathrm{kN}$ will be utilized as an force mean value in coming reliability calculation for the first FEM model. The displacement results from the three loading forces, taken up to three significant figures, are linear, although the overall physical model is non-linear.

The pile under consideration in the second subsoil model condition is shown in Figure 3. It is also transversely loaded and placed at the soil cylinder center, but in this case the subsurface has an elastic modulus randomly increasing with depth.

Loading and boundary conditions in displacements established on outer surfaces let us to simplify the problem by using the same plane of symmetry, as it was done in the first FEM model. In this example, the pile head is loaded tangentially with a resultant force of $25 \mathrm{kN}$ which is half the total mean pile load of $50 \mathrm{kN}$. The pile, similar to the first model, has a diameter of $40 \mathrm{~cm}$ and penetrates $10 \mathrm{~m}$ into the subsurface. The subsurface in this model is composed of two layers. The upper weak layer has a thickness of $9.0 \mathrm{~m}$ and is characterized by a linearly increasing expected value of the elastic modulus with depth. The expected value of the elastic modulus near the surface is $4 \mathrm{MPa}$ while the expected value of the gradient $k$ is $1.6 \mathrm{MPa} / \mathrm{m}$. The lower layer is made of a deterministic medium with a constant elastic modulus of $80 \mathrm{MPa}$ indicating favorable geotechnical properties. The pile penetrates $1 \mathrm{~m}$ into the lower layer. Both layers are considered ideally linear elastic and have a unit weight and Poisson's ratio of $\gamma=18 \mathrm{kN} / \mathrm{m}^{3}$ and $v=0.25$, respectively.

The pile properties are assumed to be equivalent to class $\mathrm{C} 25 / 30$ concrete with a unit weight $\gamma=24 \mathrm{kN} / \mathrm{m}$, Young's modulus $E_{b}=30 \mathrm{GPa}$ and Poisson's ratio $v=0.2$. In the FEM calculation the pile is discretized

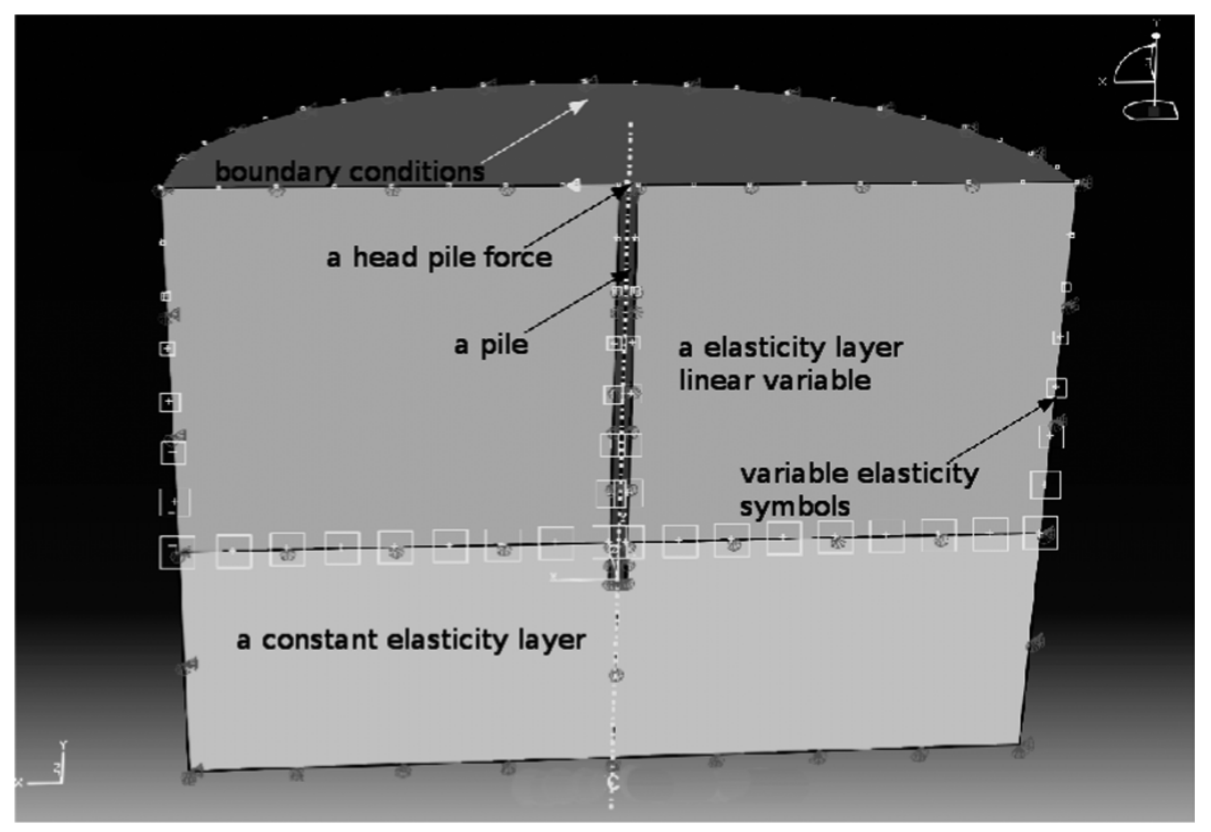

Fig. 3. The pile under consideration in the second subsoil model 
by volume finite elements, so accounting for pile bending is done automatically.

An example of a displacement distribution, similar to both subsurface geotechnical conditions, is depicted in Figure 4. This figure shows the deformed pile at the center of the subsurface having the indicated elastic properties. In the figure, the horizontal scale depicting displacement is exaggerated by a factor of 20 compared to the vertical axis.

The first calculation step in both subsoil models is to check for linearity of force-displacement relationships at the pile head for the transversally applied force of three different magnitudes. In the first case, force magnitudes are 156, 312 and $468 \mathrm{kN}$. The force expected value is equal $312 \mathrm{kN}$. Two other values are picked arbitrary, but one should be lower than force mean value and the other higher. In the second case for the mean loading force of $50 \mathrm{kN}$ two needed force values were equal to 75 and $100 \mathrm{kN}$ and both exceeded the expected value. As it was the case for previous soil condition, the obtained results of the displacements show a linear relationship with respect to the applied load, as well. Thus, the displacement results allow the creation of a response surface, which is linear in relation to the applied load, although the calculated FEM model is physically non-linear.

The second calculation step done for both FEM model is to obtain the horizontal displacements of the pile head for a set of Young's modulus values. Parameters of the random variables related to the first FEM model are included in Table 1. Table 3 defines random variables of the second FEM model.
Horizontal displacements of the first model pile head are calculated for the Young modulus magnitudes 51.0, 55.5, 60.0, 64.4, $69 \mathrm{MPa}$ prescribed to each layer. These values are constant throughout respective layer and produce 125 pile head displacements. For expected value $60 \mathrm{MPa}$ and fifteen percent of variability the increment to is equal $0.5 \sigma$. Classical approach to creation of data set is to place expected value in the set center. In the second FEM model, Young's modulus is constant at the surface but then increases with depth according to the gradient. The surface modulus and the inside gradient of the weak layer modulus are random variables. To get the set of input data for the second FEM model the surface modulus $E_{0}$ was equal to $3.2,3.4,3.6,3.8,4.0 \mathrm{MPa}$ and values $1.28,1.36$, $1.44,1.52,1.6 \mathrm{MPa} / \mathrm{m}$ were assumed to gradient $k$. These ranges of $E_{0}$ and $k$ random variables with fifteen percent of their variability furnish 25 pile head displacement results. The data sets for $E_{0}$ and $k$ have increment of $0.35 \sigma$. All calculated values are lower than their expected one. It is intuition guided selection. The pile head displacements are calculated on the base of 3D FEM models, formally physically nonlinear due to possible slippage on pile soil interface surface. An occurrence of any type of nonlinearity, physical or geometrical, in a FEM model requires an iterative procedure. Since the iterative process is time consuming, the calculation is done using script written in the language Python (Langtangen 2008) included in the ABAQUS FEM code. The language submits automatically 125 sets of Young's moduli to the first FEM model and provides increased Young's moduli

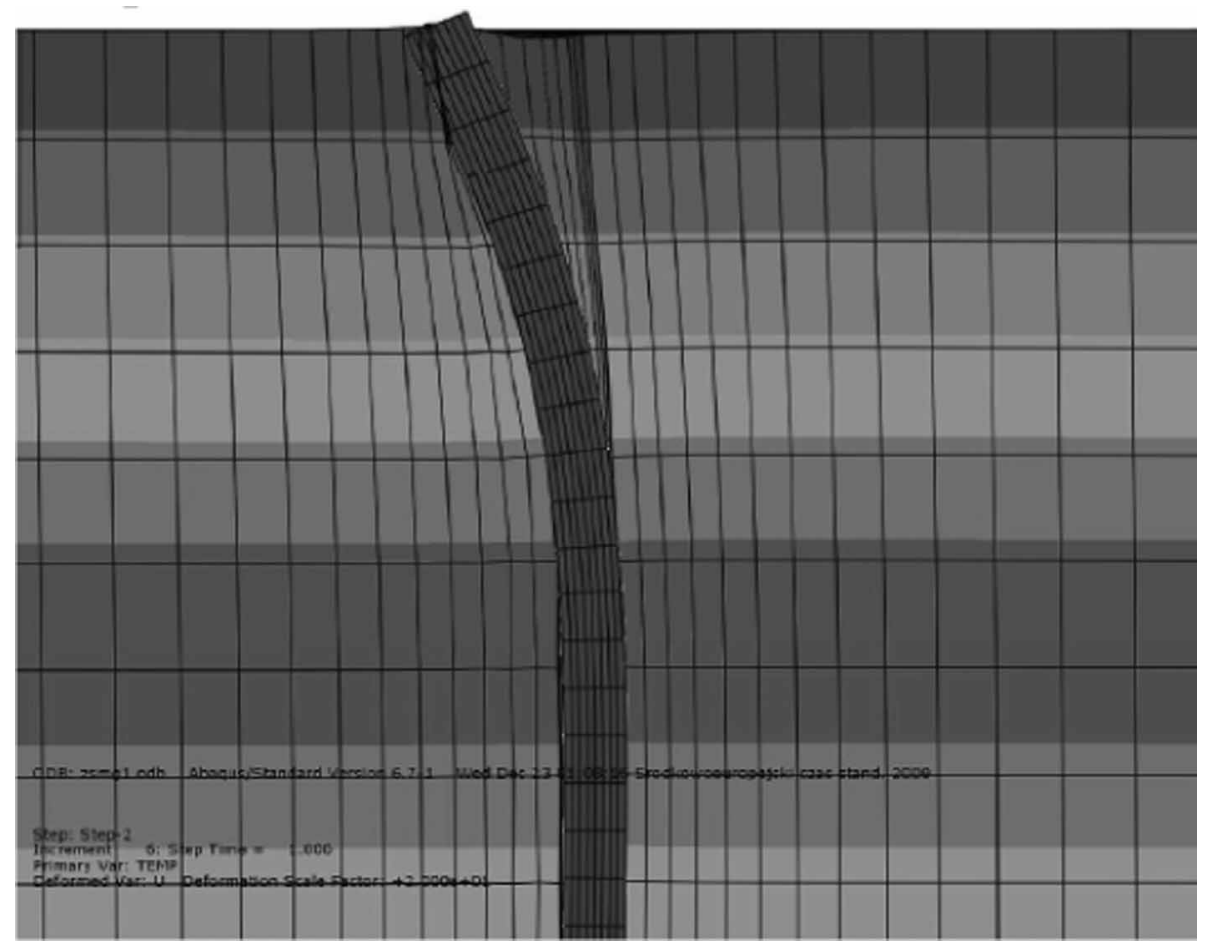

Fig. 4. An example of a displacement distribution 
Table 1. Properties of applied variables of the first model

\begin{tabular}{lccc}
\hline Parameters & Expected values & Coefficient of variation & Probability distribution \\
\hline Young's modulus of bottom layer $E_{1}$ & $60 \mathrm{MPa}$ & 0.15 & lognormal \\
Young's modulus of middle layer $E_{2}$ & $60 \mathrm{MPa}$ & 0.15 & lognormal \\
Young's modulus at/very near the surface $E_{3}$ & $60 \mathrm{MPa}$ & 0.15 & lognormal \\
Applied transverse load at the pile head $F$ & $312 \mathrm{kN}$ & 0.10 & lognormal \\
Acceptable displacement of pile head $u_{0}$ & $0.015 \mathrm{~m}$ & - & nonrandom \\
\hline
\end{tabular}

which are assigned to the particular finite element in the second model. Then, the Python program archives the results of each calculation done by the ABAQUS. The displacement sets are the input data that are used for reliability calculations. The reliability calculation is an iterative process, as well. In each iterative step, on the base of displacement data, a response surface is built. The reliability calculation, involving the response surface, defines coordinates of so-called design point (Ditlevsen, Madsen 1996). The locations of the design point are calculated by the COMREL program uses the FORM or SORM method. Coordinates of a design point are values of the random variables. Next step of iteration involves new FEM calculations for random variable values located in the vicinity of the design point. On the base of the new displacement data, a new response surface is created and a new location of the design point is found. Iteration stops when positions of the calculated design points are nearly the same in the successive iteration steps.

The successive approximation steps of calculations needs also FEM calculation guided by the script written in the language Python. These calculations were conducted using the program ABAQUS ver. 6.7 (Hibbitt et al. 2002) with the support of a grant from the Wroclaw Centre for Networking and Supercomputing, Poland.

\section{The application of probabilistic calculation methods}

The response surface method $-(\mathrm{RSM})$ is used to obtain a closed form expression for the dependence of pile head displacement on the assumed random variables in both finite element models. In both cases, the response surface takes the form of a surface of the third degree with random variables describing the elastic parameters of subsurface layers. The first calculated FEM model includes three Young's moduli, while the second uses two random variables to characterize the change of Young's modulus with depth exclusively in the upper layer.

The varying transverse loading at the pile head does not play an active role in determining the coefficients describing the response surface. Three values of the force are only used to check for linearity of the pile head displacement-applied force relationships. This is because the force is substituted into the response surface formula after the calculation results confirm that the horizontal displacement of the pile head increases linearly with the applied force.

The RSM approach applied within this study relies on numerical approximation of pile displacement received from finite element analysis. In our paper, parameters of a polynomial function, playing role of the response surface, are found by means of

Table 2. Determined response surfaces for consecutive iterations

\begin{tabular}{|c|c|c|c|c|c|c|}
\hline \multirow[b]{2}{*}{ Iterations } & \multirow{2}{*}{\multicolumn{2}{|c|}{ Polynomial coefficients }} & \multicolumn{4}{|c|}{ Design points coordinates } \\
\hline & & & $\begin{array}{c}E_{1} \\
\mathrm{MPa}\end{array}$ & $\begin{array}{c}E_{2} \\
\mathrm{MPa}\end{array}$ & $\begin{array}{c}E_{3} \\
\mathrm{MPa}\end{array}$ & $\begin{array}{c}F \\
\mathrm{kN}\end{array}$ \\
\hline 1 & $\begin{array}{l}B_{1}=2.24 \mathrm{E}-2 \\
B_{2}=6.92 \mathrm{E}-6 \\
B_{3}=-5.51 \mathrm{E}-5 \\
B_{4}=-2.75 \mathrm{E}-4 \\
B_{5}=-2.39 \mathrm{E}-8\end{array}$ & $\begin{array}{l}B_{6}=1.45 \mathrm{E}-7 \\
B_{7}=1.28 \mathrm{E}-6 \\
B_{8}=-3.99 \mathrm{E}-8 \\
B_{9}=-3.88 \mathrm{E}-8 \\
B_{10}=3.48 \mathrm{E}-7\end{array}$ & 59.4 & 54.8 & 42.0 & 410 \\
\hline 2 & $\begin{array}{l}B_{1}=2.40 \mathrm{E}-2 \\
B_{2}=-8.46 \mathrm{E}-6 \\
B_{3}=-9.95 \mathrm{E}-5 \\
B_{4}=-3.57 \mathrm{E}-4 \\
B_{5}=5.43 \mathrm{E}-8\end{array}$ & $\begin{array}{l}B_{6}=2.78 \mathrm{E}-7 \\
B_{7}=2.07 \mathrm{E}-6 \\
B_{8}=3.96 \mathrm{E}-12 \\
B_{9}=2.31 \mathrm{E}-8 \\
B_{10}=8.57 \mathrm{E}-7\end{array}$ & 59.0 & 50.9 & 37.7 & 446 \\
\hline 3 & $\begin{array}{l}B_{1}=2.59 \mathrm{E}-2 \\
B_{2}=-1.36 \mathrm{E}-5 \\
B_{3}=-1.23 \mathrm{E}-4 \\
B_{4}=-4.14 \mathrm{E}-4 \\
B_{5}=7.71 \mathrm{E}-8\end{array}$ & $\begin{array}{l}B_{6}=3.78 \mathrm{E}-7 \\
B_{7}=2.58 \mathrm{E}-6 \\
B_{8}=2.78 \mathrm{E}-8 \\
B_{9}=5.56 \mathrm{E}-8 \\
B_{10}=1.13 \mathrm{E}-6\end{array}$ & 59.1 & 50.7 & 37.4 & 445 \\
\hline
\end{tabular}


Table 3. Characteristics of variables involved in the second problem

\begin{tabular}{|c|c|c|c|}
\hline Parameters & $\begin{array}{l}\text { Expected } \\
\text { values }\end{array}$ & $\begin{array}{l}\text { Coefficient } \\
\text { of variation }\end{array}$ & $\begin{array}{l}\text { Probability } \\
\text { distribution }\end{array}$ \\
\hline $\begin{array}{l}\text { Young's modulus } \\
\text { for layer } E_{0}\end{array}$ & $4.0 \mathrm{MPa}$ & $\begin{array}{l}10 \% \\
20 \%\end{array}$ & lognormal \\
\hline $\begin{array}{l}\text { Parameter } \mathrm{k} \\
\text { describing the } \\
\text { increase of } \\
\text { Young's } \\
\text { modulus with } \\
\text { depth for the } \\
\text { layers }\end{array}$ & $1.6 \mathrm{MPa}$ & $\begin{array}{l}7.5 \% \\
10 \% \\
15 \% \\
20 \%\end{array}$ & normal \\
\hline $\begin{array}{l}\text { Transverse load on } \\
\text { pile head } F\end{array}$ & $50 \mathrm{kN}$ & $\begin{array}{l}10 \% \\
15 \%\end{array}$ & lognormal \\
\hline $\begin{array}{l}\text { Acceptable } \\
\text { displacement of } \\
\text { pile head } u_{0}\end{array}$ & $0.010 \mathrm{~m}$ & - & nonrandom \\
\hline
\end{tabular}

nonlinear regression method based on the Marquardt compromise (Marquardt 1963).

Having the response surface defined as $U(\mathbf{X})$, it is possible to conduct the probabilistic computations.

As a failure criterion, it is assumed that the limiting serviceability state condition:

$$
U(\mathbf{X})<u_{0},
$$

will not be fulfilled, where $U(\mathbf{X})$ is a displacement of the pile head and $u_{0}$ is an allowable value, given by Standards. Then the goal of the analysis is to determine the failure probability:

$$
p_{F}=\mathrm{P}\left\{U(\mathbf{X})>u_{0}\right\},
$$

where the vector $\mathbf{X}$ consists of random components. For the first subsoil condition random Variables $E_{1}$, $E_{2}, E_{3}$ are the vector $\mathbf{X}$ components and variable $E_{0}, k$ for the second one. The reliability index $\beta$ can be used as an equivalent measure of the failure probability. It is related to the probability defined in Eq. (10) by the relationship:

$$
p_{F}=\Phi_{0}(-\beta),
$$

in which $\Phi_{0}$ represents the cumulative distribution function of the standard normal distribution.

The methods FORM and SORM (Hohenbichler et al. 1987; Ditlevsen, Madsen 1996), commonly employed tools in structural reliability theory are used for estimating measures in Eqs (10) and (11). The most essential part of this method is determining the coordinates of the design point $y^{*}$, which is located on the limit state surface:

$$
\left\{x: U(x)=u_{0}\right\},
$$

and whose distance to the origin of the coordinate system after probabilistic transformation (Hochenbichler et al. 1987; Ditlevsen, Madsen 1996), is the shortest. The largest amount of "probability mass" is concentrated near the design point, so its location enables to approximates the probability in Eq. (10).

The final location of the design point is found through an iterative process by observing changes in its position related to successive response surfaces. The first response surface roughly estimates its coordinates. The better evaluation of a design point location is done on the next RS built on the base of head displacements calculated for random values taken near the design point already calculated. When the next approximation of the design point location for a new response surface does not greatly change its position, the calculation is completed and the last response surface, as well the last position of design point is accepted.

Our study uses the following iteration procedure, which is a modification of the algorithm proposed by Bauer and Puła (2000).

The approximate range of variation of the random variables for MES calculation can be determined based on their expected values. Given the expected values of particular variables, one may assume that an approximate interval of their variation is twice their standard deviation of length with the expected value in the centre, for each variable. Assuming the increment of the variable with the value of one-half the standard deviation of the random variable, it is possible to obtain five values of each random variable. If one can predict intuitively the location of the design point in relation to the expected values, then five values of random variables can be selected assuming smaller than $0.5 \sigma$ increment. For example, the increment may be equal to $0.35 \sigma$ and picking could be started from the expected value in the direction given from intuition. In former statement $\sigma$ denotes the standard deviation of the random variable under consideration. The procedure based on intuition can reduce the number of iterations.

Selecting random variables of material constants from their range of variation produces (through finite element analysis) 125 pile head displacement values for the first reliability iteration related to the first FEM model and 25 for the second one. The displacement values concerns are needed to create the starting response surfaces for both subsoil condition. The FEM calculations are a part of first iteration step of reliability analysis.

Introducing into the response surface random variable $F$, which is the horizontal force applied into the pile's head the function $U$ takes the following form, for the first model:

$$
\begin{aligned}
U\left(F, E_{1}, E_{2}, E_{3}\right)= & \frac{F}{\mathrm{E}[F]}\left(B_{1}+B_{2} E_{1}+B_{3} E_{2}+B_{4} E_{3}+\right. \\
& B_{5} E_{1}^{2}+B_{6} E_{2}^{2}+B_{7} E_{3}^{2}+B_{8} E_{1} E_{2}+ \\
& \left.B_{9} E_{1} E_{3}+B_{10} E_{2} E_{3}\right),
\end{aligned}
$$


and the following one for the second model:

$$
\begin{aligned}
U\left(F, E_{0}, k\right)= & \frac{F}{\mathrm{E}[F]}\left(B_{1}+B_{2} E_{0}+B_{3} k+B_{4} E_{0}^{2}+\right. \\
& \left.B_{5} k^{2}+B_{6} E_{0} k\right),
\end{aligned}
$$

where $\mathrm{E}[F]$ stands for expected value of the force $F$ and $B_{i}$ are parameters to be calculated. With the above regression models, the nonlinear regression program NLIN2 can be used to determine the estimates $b_{i}$ of the parameters $B_{i}$ for $F$ equal to E[F]. Estimation of $B_{i}$ magnitudes must be done for the starting and the successive response surfaces. Both response surfaces from the two subsurface profiles are linear regression models from the stand point of estimation $B_{i}$ parameters, although the response surface model is nonlinear concerning the random variables. In addition to linearity on $B_{i}$ and nonlinearity to random variable, the dependence of displacement $U$ on force $F$ is a linear one:

- The response surfaces $U\left(F, E_{1}, E_{2}, E_{3}\right)$ and $U\left(F, E_{0}, k\right)$ of the starting approximation obtained by means of this method are then substituted into Eq. (12), producing the limit state surfaces;

- Next, using the FORM or SORM method one finds the two design points $y^{*}$ that one lays on the response surface (13) and another on surfaces (14);

- The above procedure should be repeated in the vicinity of the last obtained design points with reduced range of the random variables to their standard deviations. This requires 27 FEM calculations of pile head displacements for the first model of Figure 1 and 9 for the second one of Figure 3. The new sets of the coefficients for $B_{i}$ must also be determined for these new pile head displacement values. The new $B_{i}$ parameters define response surfaces of the second iteration step and the new positions of the design points.

The coordinates of the design points determined by this method appeared accurate enough for the third step of iteration involving the third form of the response surface determined based on the first FEM model and for the second model, already the second response surface was the final one. In conducting the probabilistic calculations for the second FEM model, the intuition to predict the general location of the design point was used. This simplification speeded up computations by decreasing number of iteration steps.

\section{Results of the probabilistic calculations}

Final response surfaces described in the previous section are a basis in evaluating probability measures defined by Eqs (10) and (11). The first calculated example related to FEM three layer model shows how to obtain the final form of the response surface of
Eq. (13) by iteration of the design point location. The final response surface and design point location enables to define the sensitivity coefficients, which describes the contribution of each random variable to the reliability index beta. In order to determine which subsurface layer influences the reliability index to the greatest extent, the expected values of Young's modulus for the three layers is assumed to have the same expected value of $60 \mathrm{MPa}$ and the same variability. The assumptions concerning the probabilistic properties of the random model parameters are displayed in Table 1.

All random variables are treated as stochastically independent. The values of Poisson's ratio are assumed to be nonrandom because their randomness in many elasticity studies was determined to be negligible (Puła, Wyjadłowski 1999). It is assumed that response surfaces take a polynomial form presented by Eqs (13) and (14) as it was stated in Section 5. A satisfying convergence applied to the first FEM model was achieved in three iteration steps. Table 2 displays the coordinates of the design points as well as the polynomial coefficients of the response surfaces that were obtained in each of the three iteration steps. As shown in the Table 2, the design point coordinates in iterations 2 and 3 are very similar. Thus, the procedure is finished after the third iteration. The response surface obtained in the third step is applied to the limit state surface Eq. (12) in order to calculate the probability Eq. (10) and the corresponding reliability index $\beta$ leads to the following result:

$$
p_{F}=5.49 \cdot 10^{-7}, \beta=4.87
$$

In this type of problem, the sensitivity of the reliability index on the variation of each random variable is particularly relevant. From the presented results in Figure 5, resulting from the above computations it is evident that the random variable of the applied transverse force $F$ is most meaningful. The sensitive coefficient related to force $F$ is equal to -0.741947 . Minus means that an increase of the force $F$ produces a decrease in value of index $\beta$ among the subsurface parameters, the variation of the modulus $E_{3}$ in the top layer is the most significant even though the thickness of this layer is assumed to be only $1.0 \mathrm{~m}$. The sensitive

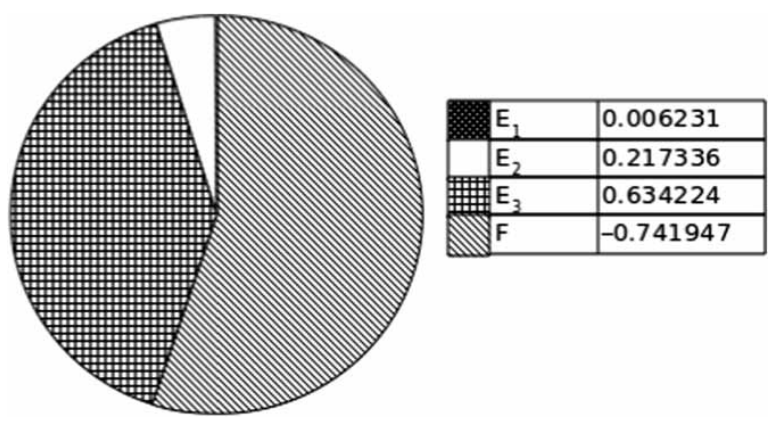

Fig. 5. Computation results 
coefficient of 0.634224 magnitude related to the $E_{3}$ modulus means that the top layer contributes the most to the index beta value.

The second calculated example analyses the influence of the coefficients of variation of the random variables on the probability of pile failure. In addition to reliability indices obtained for uncorrelated random variables, the sensitivity coefficients were analysed. Then an influence of correlation of the variables on the reliability index of the horizontally loaded pile was examined. For this case, the calculations were conducted for the following random variables: applied transverse force, $F$, Young's modulus, $E_{0}$, of the surface value and the subsoil parameter $k$ describing the increase in Young's modulus with depth. The assumptions concerning the probabilistic properties of the random parameters in the model are presented in Table 3.

In the first part of the calculation, all random variables are treated as stochastically independent. In the next part, the correlation between the random variable Young's modulus, $E_{0}$, and the gradient of the modulus parameter $k$ is assumed to be positive and negative with the values of $\rho=-0.50, \rho=+0.50, \rho=+0.75$.

The values of Poisson's ratio are nonrandom because their randomness in many elastic studies was found to be negligible (Puła, Wyjadlowski 1999). The response surfaces take the form of a polynomial with three variables of the third degree in the form of Eq. (14) according to the procedure presented in Section 5. A satisfying convergence was achieved in two iterations. Table 4 displays the coefficients obtained from the iterations.

Table 5 displays results of the reliability index and probability of failure for two different sets of coefficients of variation for each random variable. The random variables in the examples were stochastically independent. Also shown are the coordinates of design points. The last three columns display the sensitivity coefficients of each variable with the sum of their squares equaling to 1 .

The sensitivity coefficients provide information as to which random variable has the largest influence on the reliability index (probability of failure). It is evident that the random variable of the applied force has the largest influence on the reliability index, even though the assumed variation of the other random variables are relatively large. Among the two parameters character-

Table 4. Calculated response surface coefficients

\begin{tabular}{lccc}
\hline Iteration & $B_{1}$ & $B_{2}$ & $B_{3}$ \\
\hline 1 & 0.22894 & 0.35919 & -0.34252 \\
2 & 0.23580 & 0.38686 & -0.37038 \\
Iteration & $B_{4}$ & $B_{5}$ & $B_{6}$ \\
\hline 1 & 0.020784 & 0.022110 & 0.038634 \\
2 & 0.023439 & 0.024741 & 0.044512 \\
\hline
\end{tabular}

Table 5. Example results with the sensitivity coefficients

\begin{tabular}{|c|c|c|c|c|c|}
\hline \multirow{2}{*}{$\begin{array}{l}\text { Coefficients } \\
\text { of variation }\end{array}$} & \multirow[b]{2}{*}{$\beta$} & \multirow[b]{2}{*}{$p_{F}$} & \multicolumn{3}{|c|}{$\begin{array}{l}\text { Coordinates of the } \\
\text { calculation point }\end{array}$} \\
\hline & & & $E^{*}$ & $k^{*}$ & $F^{*}$ \\
\hline $\begin{array}{l}v_{F}=10 \% \\
v_{E}=10 \% \\
v_{k}=10 \%\end{array}$ & 2.485 & $6.47 \mathrm{E}-03$ & 3.54977 & 1.52557 & 49.3129 \\
\hline $\begin{array}{l}v_{F}=15 \% \\
v_{E}=20 \% \\
v_{k}=20 \%\end{array}$ & 1.53 & $6.30 \mathrm{E}-02$ & 3.3253 & 1.48291 & 47.3704 \\
\hline & & & \multicolumn{3}{|c|}{ Sensitivity coefficients } \\
\hline $\begin{array}{l}\text { Coefficients } \\
\text { of variation }\end{array}$ & $\beta$ & $p_{F}$ & $\alpha_{E}$ & $\alpha_{k}$ & $\alpha_{F}$ \\
\hline $\begin{array}{l}v_{F}=10 \% \\
v_{E}=10 \% \\
v_{k}=10 \%\end{array}$ & 2.485 & $6.47 \mathrm{E}-03$ & 0.463 & 0.188 & -0.866 \\
\hline $\begin{array}{l}v_{F}=15 \% \\
v_{E}=20 \% \\
v_{k}=20 \%\end{array}$ & 1.53 & $6.30 \mathrm{E}-02$ & 0.551 & 0.242 & -0.799 \\
\hline
\end{tabular}

izing Young's modulus, the random variation of the modulus values at the surface $E_{0}$ are most important. Naturally, a substantial increase in the coefficient of variation causes a decrease in the reliability index and also changes the coordinates of the design point.

Table 6 presents the reliability index $\beta$ regarding different values of the coefficient of variation for independent random variables $E_{0}$ and $k$.

Table 7 displays the reliability indices $\beta$ from the correlated random variables $E_{0}$ and $k$. The effect of the positive and negative correlation of variables $E_{0}$ and $k$ is clearly evident in Table 7. This positive correlation decreases the reliability indices and probability of failure is larger. On the other hand, negative correlation increases reliability indices and probability of failure goes down. Both results are in good agreement with the intuition.

\section{Concluding remarks}

This paper describes efficient procedures for the probabilistic three-dimensional analysis of pile displacements under lateral forces. The procedures are relevant to the two analysed subsurface models. Namely, the first one consists of layered linear elastic soil with each layer having a random modulus of elasticity. The second model taking the form of a linear elastic soil with a random modulus of elasticity increasing with depth.

In the both models, the conjunction of the 3-D FEM schemes with the response surface method, supported by the design point concept enabled the analysis of a non-trivial three-dimensional problem involving subsurface changes with depth. 
Table 6. Reliability indices obtained in the probabilistic calculations

\begin{tabular}{llllll}
\hline \multirow{2}{*}{$\begin{array}{l}\text { Coefficients } \\
\text { of variation }\end{array}$} & & \multicolumn{5}{c}{ Reliability indices $\beta$} \\
\cline { 4 - 6 } & & & \multicolumn{4}{c}{ Coefficient of variation $v_{k}$} \\
\cline { 4 - 6 }$v_{F}$ & $v_{E}$ & $7.50 \%$ & $10 \%$ & $15 \%$ & $20 \%$ \\
\hline $10 \%$ & $10 \%$ & 2.505 & 2.485 & 2.43 & 2.357 \\
$10 \%$ & $20 \%$ & 1.952 & 1.941 & 1.907 & 1.862 \\
$15 \%$ & $10 \%$ & 1.842 & 1.835 & 1.814 & 1.785 \\
$15 \%$ & $20 \%$ & 1.569 & 1.566 & 1.551 & 1.53 \\
\hline
\end{tabular}

The two described cases of the transversely loaded pile illustrate the influence of two types of subsurface profiles on the method of conducting probabilistic calculations. The most important difference is in the elaborating of test data obtained from subsurface investigations. In the first case, it is enough to confirm through the use of appropriate tests that the treatment of the elastic modulus as a random variable with a lognormal distribution cannot be excluded. In the second case, the regression method must be used for determining the normal distribution parameters for the appropriate model of varying with depth expected values of Young's modulus. In the described second example, the change in Young's modulus with depth is linear, although it is also possible to describe the relationship with a polynomial of the second or higher degrees.

Both pile example calculations using the applied methods of reliability theory required the following five steps:

- Perform a subsurface investigation including sample collection;

- Analyse the results from the subsurface investigation by statistical and regression methods;

- Conduct the predictive calculation with the aid of the FEM model;

- Create the response surface of the first approximation;

- Conduct the probabilistic calculation with the goal of determining the location of the design point for the first and second response surfaces as well as the reliability index for the final response surface.

Table 7. Reliability index calculated for the examples of correlated random variables

\section{Coefficients of}

variation

\begin{tabular}{lcccccc}
\cline { 5 - 6 } & & & \multicolumn{3}{c}{ Correlation coefficients $\rho$} \\
\cline { 5 - 7 }$v_{F}$ & $v_{E}$ & $v_{k}$ & & -0.50 & +0.50 & +0.75 \\
\hline $10 \%$ & $10 \%$ & $10 \%$ & 2.603 & 2.389 & 2.331 \\
$15 \%$ & $20 \%$ & $20 \%$ & 1.651 & 1.434 & 1.383 \\
\hline
\end{tabular}

Table 8. Target values of the reliability indices $\beta$ in serviceability limit state $\mathrm{C}$ - can be applied under the ultimate limit state

\begin{tabular}{lcccc}
\hline & \multicolumn{4}{c}{ Consequences of Failure } \\
\cline { 2 - 5 } $\begin{array}{l}\text { Relative cost of } \\
\text { ensuring safety }\end{array}$ & small & noticeable & moderate & large \\
\hline High & 0.0 & 1.5 & 2.3 & $3.1(\mathrm{C})$ \\
Moderate & 1.3 & 2.3 & 3.1 & $3.8(\mathrm{C})$ \\
Low & 2.3 & 3.1 & 3.8 & $4.3(\mathrm{C})$ \\
\hline
\end{tabular}

Creating the response surface of the first and second approximation again required the regression program, for example NLIN2. The probabilistic computations for determining the coordinates of the design point, reliability index, and sensitivity coefficient of each random variable were completed with the help of the FORM and SORM methods.

The obtained results of piles under horizontal loading can be evaluated from the point of view of the designer. In this case, the most important calculated parameter is the reliability index. Recommended values for the index by ISO Standard 2394:1998 (1998) are presented in Table 8.

They should be applied for limit states of serviceability. The Code recommends values of the reliability indices concern the cost of assured safety and the consequences of failure. The reliability indices beta shown in Table 8 may be used to evaluate the appropriateness of the pile design in the specific subsurface conditions. Taking into account the recommendations of the ISO Code, we may come to the conclusion that the calculated magnitude of the reliability index $\beta=$ 4.87 for the first FEM model is to high. Thus, the pile design in these conditions should be modified with the goal of reducing the value of the reliability index according to the specific value listed in Table 8 .

\section{References}

Ashour, M.; Norris, G. 2003. Lateral loaded pile response in liquefiable soil, Journal of Geotechnical and Geoenvironmental Engineering ASCE 129(5): 404-414. http:// dx.doi.org/10.1061/(ASCE)1090-0241(2003)129:6(404)

Basu, D.; Salgado, R.; Prezzi, M. 2009. A continuum-based model for analysis of laterally loaded piles in layered soils, Geotechnique 59(2): 127-140. http://dx.doi.org/ 10.1680/geot.2007.00011

Bauer, J.; Puła, W. 2000. Reliability with respects to settlement limit-states of shallow foundation on linearly-deformable subsoil, Computers and Geotechnics 26(3-4): 281-308. http://dx.doi.org/10.1016/S0266-352X(99)00043-9

Brinch Hansen, J. 1961. The ultimate resistance of rigid piles against transversal force, in Bulletin No 12 of the Danish Geotechnical Institute, 5-9.

Broms, B. B. 1964a. Lateral resistance of piles in cohesive soils, Journal of the Soil Mechanics and Foundations Division ASCE 90(2): 27-64. 
Broms, B. B. 1964b. Lateral resistance of piles in cohesionless soils, Journal of the Soil Mechanics and Foundations Division ASCE 90(3): 123-158.

Chan, C. L.; Low, B. K. 2009. Reliability analysis of laterally loaded piles involving nonlinear soil and pile behavior, Journal of Geotechnical and Geoenvironmental Engineering ASCE 135(3): 431-443. http://dx.doi.org/10. 1061/(ASCE)1090-0241(2009)135:3(431)

Cherubini, C. 1997. Data and consideration on the variability of geotechnical properties of soils, in Proc. of the ESREL Conference, June, 1997, Lisbon, Portugal, $1538-1591$.

Cherubini, C. 2000. Probabilistic approach to the design of anchored sheet pile walls, Computers and Geotechnics 26(3-4): 309-330. http://dx.doi.org/10.1016/S0266-352X(99)00044-0

Ditlevsen, O.; Madsen, H. O. 1996. Structural reliability methods. Chichester: John Wiley \& Sons. 384 p.

Fan, C.-C.; Long, J. H. 2005. Assessment of existing methods for predicting soil response for laterally loaded piles in sand, Computers and Geotechnics 32(4): 274-289.

http://dx.doi.org/10.1016/j.compgeo.2005.02.004

Faravelli, L. A. 1989. Response-surface approach for reliability analysis, Journal of Engineering Mechanics ASCE 115(12): 2763-2781. http://dx.doi.org/10.1061/ (ASCE)0733-9399(1989)115:12(2763)

Fenton, G. A.; Griffiths, D. V. 2003. Bearing capacity prediction of spatially random $c \varphi$ soils, Canadian Geotechnical Journal 40(1): 54-65. http://dx.doi.org/10.1139/t02-086

Fenton, G. A.; Griffiths, D. V. 2008. Risk assessment in geotechnical engineering. New York: John Wiley \& Sons. 480 p. http://dx.doi.org/10.1002/9780470284704

Guo, W. D. 2006. On limiting force profile, slip depth response of lateral piles, Computers and Geotechnics 33(1): 47-67.

http://dx.doi.org/10.1016/j.compgeo.2006.02.001

Haldar, S.; Sivakumar Babu, G. L. 2008. Effect of soil spatial variability on the response of laterally loaded pile on undrained clay, Computers and Geotechnics 35(4): 537-547.

http://dx.doi.org/10.1016/j.compgeo.2007.10.004

Hibbitt, D.; Karlsson, B.; Sorensen, P. 2002. ABAQUS Keywords Manual Version 6.3. Hibbitt, Karlsson \& Sorensen, Inc., USA.

Hohenbichler, M.; Gollwitzer, S.; Kruse, W.; Rackwitz, R. 1987. New light on first and second-order reliability methods, Structural Safety 4(4): 267-284. http://dx.doi.org/10.1016/0167-4730(87)90002-6

ISO 2394:1998 General principles on reliability of structures. International Standard. International Organization for Standardization, 1998. 73 p.

Langtangen, H. P. 2008. Python scripting for computational science, Texts in Computational Science and Engineering. Berlin: Springer. 756 p. http://dx.doi.org/10.1007/978-3-540-73916-6

Li, W.; Li, K.; White, W. 1987. Probabilistic characterization of soil profile. Research studies from the Department of Civil Engineering, University College, Australian Defence Force Academy, UNSW. 20 p.
Marquardt, D. W. 1963. An algorithm for least-squares estimation of non-linear parameters, Journal of the Society for Industrial and Applied Mathematics 11(2): 431-441. http://dx.doi.org/10.1137/0111030

Marquardt, D. W. 1966. NLIN2: least-squares estimation of non-linear parameters computer code. Distribution no. 309401", IBM Share Library. 77 p.

Matlock, H. 1970. Correlations for design of laterally loaded piles in soft clay, in Proc. of the Offshore Technology Conference, Houston, Texas, 1970, 577-594. http://dx.doi.org/10.4043/1204-MS

McClelland, B.; Focht, J. A. 1956. Soil modulus for laterally loaded piles, Journal of the Soil Mechanics and Foundations Division ASCE 82(4): 1-22.

Myers, R. H.; Montgomery, D. C. 1995. Response surface methodology process and product optimisation using design experiments. New York: John Wiley \& Sons. 704 p.

Poulos, H. G. 1971. Behavior of laterally loaded piles. Single piles, Journal of the Soil Mechanics and Foundations Division ASCE 97(5): 711-731.

Puła, W. 1997. Reliability analysis of rigid piles subjected to lateral loads, in Pietruszczak, S.; Pande, G. N. (Eds.). Numerical Models in Geomechanics. Balkema, Rotterdam, 521-526.

Puła, W.; Różański, A. 2005. Reliability of rigid piles subjected to lateral loads. A revised approach, Scientific Papers of the Institute of Geotechnics and Hydrotechnics of the Wroclaw University of Technology 75: 463-472.

Puła, W.; Różański, A. 2007. Reliability of rigid piles subjected to lateral loads: a response surface approach, in Proc. of the International Symposium on Numerical Models in Geomechanics: NUMOG X, 2527 April, 2007, Rhodes, Greece, 481-487.

Puła, W.; Wyjadłowski, M. 1999. Effect of elastic parameters random variability on shallow foundations settlements by finite layers method, Studia Geotechnica et Mechanica 21(3-4): 87-118.

Reese, L. C. 1997. Analysis of laterally loaded piles in weak rock, Journal of Geotechnical and Geoenvironmental Engineering ASCE 123(11): 1010-1017. http://dx.doi. org/10.1061/(ASCE)1090-0241(1997)123:11(1010)

Reese, L. C.; Van Impe, W. F. 2001. Single piles and pile groups under lateral loading. Taylor \& Francis. 463 p.

Tandjiria, V.; Teh, C. I.; Low, B. K. 2000. Reliability analysis of laterally loaded piles using response surface methods, Structural Safety 22(4): 335-355. http://dx.doi.org/10.1016/S0167-4730(00)00019-9

Xu, K. J.; Poulos, H. G. 2001. 3-D elastic analysis of vertical piles subjected to "passive" loadings, Computers and Geotechnics 28(5): 349-375. http://dx.doi.org/10.1016/S0266-352X(00)00024-0

Yang, Z.; Jeremić, B. 2005. Study of soil layering effects on lateral loading behavior of piles, Journal of Geotechnical and Geoenvironmental Engineering ASCE 131(6): 762-770. http://dx.doi.org/10.1061/(ASCE)1090-0241 (2005)131:6(762)

Zhang, L. 2009. Nonlinear analysis of laterally loaded piles in cohesionless soils, Computers and Geotechnics 36(5): 718-724.

http://dx.doi.org/10.1016/j.compgeo.2008.12.001 
Janusz KOZUBAL. Assistant of professor in the Department of Civil Engineering at Wroclaw University of Technology. He received his PhD degree from the Wrocław University of Technology in 2001. He is a member of the Polish Committee of Geotechnics. His research interests include safety and risk analysis in geotechnics as well as probabilistic and numerical methods in geomechanics and geotechnical engineering.

Wojciech PUŁA. Professor and the Chief of the Foundation Engineering Group in the Institute of Geotechnics and Hydrotechnics at Wrocław University of Technology, Poland. He received his PhD degree from the Wrocław University of Technology in 1985. He is a member International Society for Soil Mechanics and Geotechnical Engineering, Polish Committee on Geotechnics and Polish Society of Theoretical and Applied Mechanics. His research interests include safety and risk analysis in geotechnics as well as probabilistic and numerical methods in geomechanics and geotechnical engineering.

Marek WYJADLOWSKI. Assistant of professor in the Department of Civil Engineering at Wrocław University of Technology. He received his $\mathrm{PhD}$ degree from the Wrocław University of Technology. He is a member of the Polish Committee of Geotechnics and ISSMGE. His major research interests are geotechnical analysis of deformation and stability of soil structures, safety and risk analysis in geotechnics.

Jerzy BAUER. Faculty member in the Institute of Geoengineering, Geology and Mining at Wrockaw University of Technology, Poland. He received his PhD degree from the Wrocław University of Technology in 1972. As an associate visiting professor he delivered lectures at Southern Illinois University at Carbondale and New Mexico Institute of Mining and Technology. He is a member of International Society for Rock Mechanics and Polish Society of Theoretical and Applied Mechanics. His research interests include safety and risk analysis in geotechnics as well as probabilistic and numerical methods in geomechanics and geotechnical engineering. 